\title{
Coinfection with HIV and hepatitis C virus in 229 children and young adults living in Europe
}

\section{The European Paediatric HIV/HCV Co-infection Study Group in the European Pregnancy and Paediatric HIV Cohort Collaboration (EPPICC) in EuroCoord*}

\begin{abstract}
Objective: To characterize children, adolescents and young adults infected with HIV/ hepatitis $\mathrm{C}$ virus $(\mathrm{HCV})$ vertically or before age of 18 years and living in Europe regarding mode of acquisition, HCV genotype, clinical status and treatment.

Design: Retrospective, cross-sectional study using pooled data from 11 European paediatric HIV cohorts.

Methods: Patients aged more than 18 months and less than 25 years, with HIV/HCV acquired vertically or in childhood, were included. Anonymized individual patient data were collected using a standard protocol and modified HIV Cohorts Data Exchange Protocol.

Results: Of 229 patients included, $142(62 \%)$ had vertically acquired infection. Median age at last follow-up was 16.2 years. Most children had HCV genotype 1 (101/184, $55 \%)$ or $3(57 / 184,31 \%)$. One-fifth (46/214) had a previous AIDS diagnosis (data missing on prior AIDS diagnoses for 15). At their last clinic visit, 70\% (145/208) had no/mild immunosuppression (Centers for Disease Control and Prevention stage 1), and 131 of 179 on antiretroviral therapy had undetectable HIV RNA (assay thresholds varied from $<20$ to $<150$ copies/ml). Overall, $42 \%$ (86/204) had hepatomegaly in the previous year, and $55 \%(116 / 213)$ had alanine aminotransferase more than $40 \mathrm{IU} / \mathrm{l}$ at their last test. Of 97 patients with transient elastography, 12 had results more than $9 \mathrm{kPa}$; this was associated with duration of $\mathrm{HCV}$ infection $(P=0.033)$, but not with $\mathrm{CD}^{+}$cell count, antiretroviral therapy use or sex in univariable analysis. Of 17 patients with liver biopsies, six had bridging fibrosis and one had cirrhosis. Twenty-five (11\%) had been treated successfully for HCV.
\end{abstract}

Conclusion: The high proportion of patients with progressive liver disease underscores the need for close monitoring and earlier and more effective HCV treatment.

Copyright $\odot 2016$ Wolters Kluwer Health, Inc. All rights reserved.

AIDS 2017, 31:127-135

Keywords: coinfection, hepatitis C, HIV, paediatric, vertical infection

\section{Introduction}

Worldwide, around $20-30 \%$ of the 34 million HIVinfected individuals are estimated to have chronic $\mathrm{HCV}$ infection, although rates of $\mathrm{HIV} / \mathrm{HCV}$ coinfection vary between and within populations [1]. Adult studies have demonstrated that HIV modifies the natural history of
HCV infection, with increased probability of chronicity after infection, higher HCV viral load and accelerated liver disease progression amongst those chronically infected [24]. Chronic HCV infection is the main cause of liver disease and mortality in HIV-infected adults and also contributes to extrahepatic morbidity and mortality through immune activation and chronic inflammation [1,5].

Correspondence to Dr Claire Thorne, Population, Policy and Practice Programme, UCL Institute of Child Health, University College London, 30 Guilford Street, London WC1N 1EH, UK.

Tel: +44 0207905 2105; e-mail: Claire.thorne@ucl.ac.uk

* Details of the European Paediatric HIV/HCV Co-infection Study Group in the European Pregnancy and Paediatric HIV Cohort Collaboration (EPPICC) in EuroCoord are given in the Acknowledgements.

Received: 18 May 2016; revised: 14 September 2016; accepted: 19 September 2016. 
Although HCV coinfection in HIV-infected adults has been much studied from epidemiological and clinical perspectives, with a current focus on HCV treatment with direct acting antivirals (DAAs) [6], much less is known about HIV/HCV coinfection in childhood and adolescence. The few studies on HIV/HCV coinfected children and adolescents to date have been small and limited to single hospitals or countries, and thus important questions remain with respect to $\mathrm{HCV}$ genotype distribution, disease progression and availability and response to HCV treatment $[7,8]$. Such changes are compounded by striking gaps in our understanding of the natural history of HCV infection in children without coinfection. For example, little is understood about the subgroup of children who progress to serious liver disease during childhood or the impact of HCV-related inflammation on extrahepatic manifestations.

Most children with $\mathrm{HIV} / \mathrm{HCV}$ coinfection acquire this vertically from their mothers $[9,10]$ or through nosocomial transmission in healthcare settings, although the latter route is now limited to specific lower-income and middle-income settings in which blood and medical injecting safety remains inadequate [11]. Adolescents may also acquire HIV/HCV coinfection horizontally. Young people who inject drugs may be particularly vulnerable to acquisition of blood-borne viruses, reflecting poor access to harm-reduction services and risky injecting practices; increases in injecting drug use among adolescents and young people, with accompanying outbreaks of $\mathrm{HIV}$ and/or HCV, have been reported in Europe [12], as well as in the United States [13].

We conducted a descriptive epidemiological study of $\mathrm{HIV} / \mathrm{HCV}$ coinfection in children, adolescents and young adults infected with $\mathrm{HIV} / \mathrm{HCV}$ vertically or before age 18 years within our European paediatric HIV cohort collaboration to characterize this subpopulation with respect to mode of acquisition, HCV genotype, clinical status and treatment.

\section{Methods}

We conducted a retrospective, cross-sectional observational study, using pooled data from paediatric HIV cohorts in the European Pregnancy and Paediatric HIV Cohort Collaboration that conducts epidemiological research on HIV-infected pregnant women and children [14] and was part of the EuroCoord network (www. eurocoord.net).

Children aged more than 18 months, adolescents and young adults aged less than 25 years, with HIV and chronic HCV coinfection acquired vertically or in childhood (i.e. up to age of 18 years), irrespective of acquisition route, were eligible for inclusion. It is difficult to establish age at acquisition of infection in patients infected through injecting drug use. We included in our study population 34 young people (all living in eastern Europe) who were reported as having acquired HCV via injecting drug use, but were not diagnosed until aged 1824 years, including three patients whose HIV infection was nosocomially acquired in childhood. The rationale for including this group of 34 young people was that the majority likely acquired HCV infection before age of 18 years, given that initiation of injecting drug use usually starts in mid-adolescence in this setting [15]. Patients with positive anti-HCV antibodies who spontaneously cleared HCV (i.e. disappearance of HCV RNA in at least 2 consecutive serum samples taken 6 months apart) were excluded. Age more than 18 months was chosen as inclusion criteria to rule out misdiagnoses due to the presence of passively transferred maternal antibodies [16].

Eleven cohorts from 10 countries provided anonymized individual patient data, collected according to a standard protocol, with data specification based on the HIV Cohorts Data Exchange Protocol (www.hicdep.org). Variables included socio-demographics, data on HCV and HIV acquisition, disease and treatment, laboratory tests and liver investigations (e.g. biopsy, transient elastography).

\section{Definitions}

Patients were considered chronically infected if $\mathrm{HCV}$ RNA was detected in at least two blood samples at least 6 months apart; we included chronically infected patients who subsequently achieved sustained virologic response (SVR) following treatment. HIV-1 infection was defined on the basis of detection of HIV-1 antibody and/or positive HIV RNA or DNA PCR in at least two blood samples.

For patients with vertically acquired $\mathrm{HCV}$, birthdate was used as presumed date of HCV infection. For the remainder, HCV diagnosis date was used as proxy date of infection, with calculated duration of HCV infection therefore a minimum estimate. Geographic region of residence was defined as central and eastern Europe (Poland, Romania, Russia and Ukraine), northern Europe (Belgium, Germany, Switzerland and United Kingdom) and southern Europe (Italy and Spain).

HIV-associated immunodeficiency was defined as none or mild, moderate and severe based on Centers for Disease Control and Prevention 1994 classification [17]. The limit of detection of HIV RNA assays ranged from less than 20 to less than 150 copies $/ \mathrm{ml}$. The upper limit of normal (ULN) cut-off for aspartate aminotransferase (AST) and alanine aminotransferase (ALT) was defined as 40 IU/1. Division of AIDS classification for grading the severity of adverse events was used to classify ALT and AST elevations [18].

Liver fibrosis stages evaluated by liver biopsy scoring systems other than METAVIR were reassigned 
Table 1. Socio-demographic and clinical characteristics, by mode of HCV acquisition.

\begin{tabular}{|c|c|c|c|}
\hline \multirow[b]{3}{*}{ N } & Vertical acquisitio & Other acquisition & \\
\hline & \multicolumn{2}{|c|}{$N(\%)$} & \\
\hline & 145 & 84 & \\
\hline \multicolumn{4}{|l|}{ Country of residence } \\
\hline Belgium & $2(1.4)$ & $1(1.2)$ & \\
\hline Germany & $1(0.7)$ & 0 & \\
\hline Italy & $19(13.1)$ & $1(1.2)$ & \\
\hline Poland & $3(2.1)$ & $1(1.2)$ & \\
\hline Romania & 0 & $33(39.3)$ & \\
\hline Russia & $18(12.4)$ & $31(36.9)$ & \\
\hline Spain & $44(30.3)$ & $2(2.4)$ & \\
\hline Switzerland & $3(2.1)$ & 0 & \\
\hline UK & $2(1.4)$ & $1(1.12)$ & \\
\hline Ukraine & $53(36.6)$ & $14(16.7)$ & \\
\hline \multicolumn{4}{|l|}{ Region of origin } \\
\hline CE Europe & $74(51.0)$ & $79(94.0)$ & \\
\hline N Europe & $3(2.1)$ & 0 & \\
\hline S Europe & $52(35.9)$ & $3(3.6)$ & \\
\hline Africa & $2(1.4)$ & $2(2.4)$ & \\
\hline Missing/unknown & $14(9.7)$ & 0 & $P<0.001$ \\
\hline \multicolumn{4}{|l|}{ Current HIV clinical stage } \\
\hline Not symptomatic & $5(3.4)$ & 0 & \\
\hline CDC ANWHO 1 or 2 & $47(32.4)$ & $29(34.5)$ & \\
\hline CDC B/WHO 3 & $52(35.9)$ & $27(32.1)$ & \\
\hline CDC C/WHO 4 & $24(16.6)$ & $17(20.2)$ & \\
\hline Unknown & $17(11.7)$ & $11(13.1)$ & $P=0.45$ \\
\hline \multicolumn{4}{|l|}{ Current CDC immune stage } \\
\hline None or mild suppression & $101(69.7)$ & $44(52.4)$ & \\
\hline Moderate suppression & $24(16.6)$ & $29(34.5)$ & \\
\hline Severe suppression & $6(4.1)$ & $4(4.8)$ & \\
\hline Unknown & $14(9.7)$ & $7(8.3)$ & $P=0.018$ \\
\hline \multicolumn{4}{|l|}{ Age at last follow-up (years) } \\
\hline$<11$ & $60(41.4)$ & $7(8.3)$ & \\
\hline $11-17$ & $42(29.0)$ & $24(28.6)$ & \\
\hline $18-24$ & $43(29.7)$ & $53(63.1)$ & $P<0.001$ \\
\hline \multicolumn{4}{|l|}{ Age at HCV diagnosis } \\
\hline Median (IQR) (years) & $2.3(1.5,6.0)$ & $17.3(10.0,21.5)$ & $P<0.001$ \\
\hline \multicolumn{4}{|l|}{ HCV genotype } \\
\hline 1 & $66(45.5)$ & $35(41.7)$ & \\
\hline 2 & $4(2.8)$ & $1(1.2)$ & \\
\hline 3 & $40(27.6)$ & $17(20.2)$ & \\
\hline 4 & $17(11.7)$ & $4(4.8)$ & \\
\hline Unknown & $18(12.4)$ & $27(32.1)$ & $P=0.50$ (among known values) \\
\hline
\end{tabular}

$\mathrm{IQR}$, interquartile range.

METAVIR fibrosis stage [19]. Two surrogate biomarkers for liver fibrosis were used: AST-to-platelet ratio index (APRI) and the FIB-4 score, which have been validated in HIV/HCV coinfected adults [20,21], but not children. APRI was calculated using the formula APRI $=(\mathrm{AST} /$ ULN)/platelets $\left(10^{9} / 1\right) \times 100$ [22]. An APRI score more than 1.5 was taken as a predictor of significant fibrosis [21-23]. The FIB-4 score was calculated using the formula $\mathrm{FIB}-4=[$ age (years) $\times$ AST $(\mathrm{U} / \mathrm{l})] /[$ platelets $\left(10^{9} / 1\right) \times$ ALT $\left.(\mathrm{U} / 1)^{\mathrm{P} / 2}\right][20]$. A FIB-4 score more than 3.25 was taken as an indicator of advanced fibrosis [20].

Medians are presented with interquartile range (IQR) and were compared using the Wilcoxon-Mann-Whitney test. Univariable comparisons were assessed using the $\chi^{2}$ test for trend. Comparisons of clinical status and laboratory markers were conducted using data from the most recent visit date or the last available measurement, with the exception of those patients who achieved a SVR following $\mathrm{HCV}$ treatment, for whom the last measure prior to treatment was used. Statistics were conducted using SAS version 9.3 (SAS Institute Inc., Cary, North Carolina, USA).

\section{Results}

A total of $229 \mathrm{HCV} / \mathrm{HIV}$ coinfected children and young people were included, of whom 98 were men and 130 women (one missing sex). Median age at last clinical follow-up was 16.2 years (IQR 10.0, 20.2); this was higher in northern and southern Europe than in central and eastern Europe (18.1 versus 13.8 years, $P<0.001$ ). Overall, 206 participants were white, four were 
black-African, two were Asian and the rest (17, 7\%) had missing ethnicity. Socio-demographic and key clinical characteristics are presented in Table 1 , stratified by mode of acquisition. A total of 145 (63\%) had acquired HCV vertically, 15 (7\%) nosocomially, 40 (17\%) through injecting drug use and 29 (13\%) had unknown mode of acquisition. Mode of HIV acquisition was usually consistent with that for HCV infection, although three Romanian patients nosocomially infected with HIV in childhood acquired HCV through injecting drug use (HCV diagnosed at ages 17, 19 and 23 years). There were 34 patients who were diagnosed with HCV at at least 18 years (median age 21 years) overall.

One-fifth $(46 / 214,21 \%)$ of patients had a history of AIDS (15 missing data), with median age at AIDS diagnosis of 5.1 years (IQR 1.5, 10.1); HIV encephalopathy was the most common AIDS-defining condition $(n=11)$, followed by Pneumocystis jirovecii pneumonia $(n=8)$ and Mycobacterium tuberculosis ( $n=7$ pulmonary, $n=3$ extrapulmonary). Overall, 5\% (10/213) had severe immunosuppression at their most recent clinical visit (Table 1), with $70 \%(145 / 213)$ having no or mild immunosuppression. Most (179/218) patients were on antiretroviral therapy (ART). Among 179 on ART, 131 (73\%) had undetectable HIV RNA at their most recent visit.

Overall, HCV genotype was known for 184 (80\%) patients, with genotype 1 and genotype 3 predominating and comprising overall 44 and $25 \%$, respectively (Table 1 ). Fifty-eight percent $(65 / 113)$ of patients living in central and eastern Europe and 55\% (34/62) in southern Europe had genotype 1 infection, compared with $22 \%(2 / 9)$ in northern Europe, where the largest proportion of patients had genotype 4 (4/9). Figure 1 presents duration of HCV infection by mode of acquisition; median duration was 13.3 years (IQR 8.6, 18.1) among those vertically infected, although regional differences were apparent, with a median duration of 9.3 years (IQR 5.7, 10.8) in central and eastern Europe, 18.0 years (IQR 17.9, 18.1) in northern Europe and 18.2 years (IQR 16.1, 20.1) in southern Europe $(P<0.001)$.

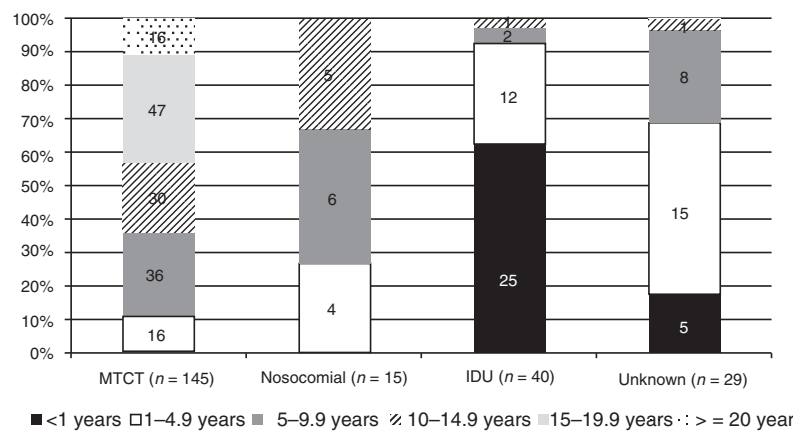

Fig. 1. Duration of HCV infection, by mode of acquisition.
Among 204 patients with data on presence of hepatomegaly and/or splenomegaly during the previous 12 months of follow-up, $86(42 \%)$ had isolated hepatomegaly, 39 (19\%) had isolated splenomegaly and 35 (17\%) had hepatosplenomegaly. A smaller proportion of vertically infected patients had hepatomegaly compared with those with other acquisition modes [36.7\% (51/139) versus $56.4 \%(35 / 62), P<0.01]$, but the proportion with splenomegaly did not vary between these groups $[18.8 \%$ $(26 / 138)$ versus $20.6 \%(13 / 63), P=0.77]$.

ALT measurements were available for 213 patients and AST for 111 patients, of whom 116 (55\%) and 68 (61\%), respectively, had levels above the ULN at their most recent test. A significantly greater proportion of patients with nonvertically acquired HCV had elevated liver enzymes compared with vertically infected individuals (Table 2). APRI and FIB-4 scores are summarized in Table 2. A total of 97 children and young people had transient elastography results available (Table 2), with median age at investigation of 17.6 years (IQR 13.0, 21.6). Of the 12 patients with transient elastography results more than $9.5 \mathrm{kPa}$, eight had genotype $1(67 \%)$ and two each had genotype 3 and genotype 4. Duration of $\mathrm{HCV}$ infection among those with transient elastography results of less than $9.5 \mathrm{kPa}$ was significantly lower $(10.7$ years, IQR $3.7,18.0)$ compared with patients with greater liver stiffness (18 years, IQR 13.9, 19.2) $(P=0.033)$. There was no association between transient elastography results and $\mathrm{CD}^{+}{ }^{+}$cell count categories, ART use or sex in univariable analysis.

Seventeen (8\%) patients from eight cohorts had results from at least one liver biopsy reported. Twelve (71\%) of these patients had acquired HCV vertically, one via IDU and three nosocomially (one unknown). Median age at first biopsy was 13 years (range, 3-22). There was no association between transient elastography results and having a biopsy $(P=0.22)$ or with having an elevated ALTor AST $(P=0.60)$. Seven patients had a fibrosis score of $\mathrm{F} 3$ and one of $\mathrm{F} 2$, with the remainder having no fibrosis or portal fibrosis without septa; moderate inflammation was present in 13 biopsies and mild inflammation in three. Two patients had repeat liver biopsies: one child, aged 9 and 11.5 years at first and second biopsies, respectively, had improvement of both fibrosis and inflammation by one score with no HCV treatment given. The second young person (vertically infected, genotype 3a), aged 14 and 19.5 years at first and second biopsies, respectively, progressed from periportal and portal fibrosis to cirrhosis and died of decompensated cirrhosis aged 21 years.

Overall, $174(76.0 \%)$ of the 229 patients were HCV treatment-naïve, 25 (10.9\%) had been unsuccessfully treated with pegylated interferon and ribavirin (pegIFN/ RBV), five (2.2\%) had completed pegIFN/RBV treatment but were awaiting 24-week posttreatment SVR (SVR24) result and $25(10.9 \%)$ had been treated 
Table 2. Liver enzyme measures, noninvasive markers of fibrosis and transient elastography.

\begin{tabular}{|c|c|c|c|c|}
\hline & Vertically acquired HCV & $\mathrm{HCV}$ acquired by other routes & & \\
\hline & & $(\%)$ & & Total \\
\hline \multicolumn{5}{|l|}{ ALT } \\
\hline Number with measurement available ${ }^{a}$ & 131 & 82 & & 213 \\
\hline \multicolumn{5}{|l|}{ DAIDS grading } \\
\hline Nonelevated & $83(63.4)$ & $33(40.2)$ & & $116(54.5)$ \\
\hline Mild elevation (grade 1) & $37(28.2)$ & $29(35.4)$ & & $66(31.0)$ \\
\hline Moderate elevation (grade 2 ) & $11(8.4)$ & $13(15.9)$ & & $24(11.3)$ \\
\hline Severe elevation (grade 3 ) & 0 & $7(8.5)$ & $P=0.0007^{\mathrm{b}}$ & $7(3.3)$ \\
\hline \multicolumn{5}{|l|}{ AST } \\
\hline Number with measurement available ${ }^{a}$ & 77 & 34 & & 111 \\
\hline \multicolumn{5}{|l|}{ DAIDS grading } \\
\hline Nonelevated & $47(61.0)$ & $15(44.1)$ & & $62(55.9)$ \\
\hline Mild elevation (grade 1 ) & $27(35.1)$ & $8(23.5)$ & & $35(31.5)$ \\
\hline Moderate elevation (grade 2 ) & $2(2.6)$ & 7 (20.6) & & $9(8.1)$ \\
\hline Severe elevation (grade 3 ) & $1(1.3)$ & $4(11.8)$ & $P=0.0002^{\mathrm{b}}$ & $5(4.5)$ \\
\hline \multicolumn{5}{|l|}{ APRI } \\
\hline Number with biomarker available & 79 & 48 & & 127 \\
\hline \multicolumn{5}{|l|}{ APRI score } \\
\hline$<0.5$ (no significant fibrosis) & $45(57.0)$ & $12(25.0)$ & & $57(44.9)$ \\
\hline $0.5-1.5$ & $29(36.7)$ & $23(47.9)$ & & $52(40.9)$ \\
\hline$>1.5$ (significant fibrosis) & $5(6.3)$ & $13(27.1)$ & $P=0.0002$ & $18(14.2)$ \\
\hline \multicolumn{5}{|l|}{ FIB-4 } \\
\hline Number with biomarker available & 79 & 48 & & 127 \\
\hline \multicolumn{5}{|l|}{ FIB-4 groups } \\
\hline$\leq 1.45$ (no advanced fibrosis) & $73(92.4)$ & $41(85.4)$ & & $114(89.8)$ \\
\hline $1.46-3.25$ & $5(6.3)$ & $6(12.5)$ & & $11(8.7)$ \\
\hline$>3.25$ (advanced fibrosis/cirrhosis) & $1(1.3)$ & $1(2.1)$ & & $2(1.6)$ \\
\hline \multicolumn{5}{|l|}{ Transient elastography } \\
\hline Number with measurement available & 62 & 35 & & 97 \\
\hline \multicolumn{5}{|l|}{ Liver stiffness $(\mathrm{kPa})$} \\
\hline$<5.8$ & $30(48.4)$ & $11(31.4)$ & & $41(42.3)$ \\
\hline $5.9-9.5$ & $23(37.1)$ & $21(60.0)$ & & $44(45.4)$ \\
\hline $9.6-12.5$ & $6(9.7)$ & $2(5.7)$ & & $8(8.2)$ \\
\hline$>12.5$ & $3(4.8)$ & $1(2.9)$ & $P=0.09^{\mathrm{c}}$ & $4(4.1)$ \\
\hline
\end{tabular}

ALT, alanine aminotransferase; AST, aspartate aminotransferase; APRI, AST-to-platelet ratio index; DAIDS, Division of AIDS.

${ }^{\mathrm{a} A t}$ last clinic visit.

${ }^{b} \chi_{2}^{2}$ test with grades 2 and 3 grouped together.

${ }^{c} \chi^{2}$ test with $9.6-12.5$ and more than 12.5 grouped together.

successfully. Median age at initiation of pegIFN/RBV treatment was 17.2 years (IQR 3.5, 24.0). HCV genotype distribution was $28(51 \%)$ genotype 1 , one genotype 2 , 21 (38\%) genotype 3 and three (5\%) genotype 4 (two missing). Forty-seven (85\%) of the patients on pegIFN/RBV were receiving concurrent ART. The SVR 24 rates were $32 \%(8 / 25)$ for genotype 1 and $79 \%$ $(15 / 19)$ for genotype 3 ; the one treated patient with genotype 2 achieved an SVR24, but none of the three treated patients with genotype 4 did so.

In addition to the death above, one other vertically infected patient died following Pneumocystis jirovecii pneumonia at age 20 years.

\section{Discussion}

In this study, we have characterized the population of children and young people living with vertically or childhood-acquired HIV/HCV coinfection and followed in European paediatric HIV cohorts. No previous description of the HIV/HCV epidemic in children and adolescents across the European region exists. We demonstrate some important regional differences, show that chronic HCV infection in the presence of HIV coinfection is associated with progressive liver disease in a substantial proportion of these children and young people and highlight the low HCV treatment rates.

The cohort of vertically infected patients living in northern and southern Europe were older than those living elsewhere. This reflects the general ageing of paediatric HIV cohorts, declining HIV mother-to-child transmission (MTCT) and the decreasing HCV prevalence in HIV-positive women in these regions [24,25]. In contrast, central and eastern Europe has a younger HIV epidemic, higher HIV MTCT rates (particularly among women who inject drugs, reflecting poorer access to optimum interventions) and a greater proportion of $\mathrm{HIV} / \mathrm{HCV}$ coinfected pregnant women $[26,27]$. In our study, similar to the adult genotype distribution in Global 
Burden of Disease European regions reported in a recent meta-analysis [26], genotype 1 was the most common followed by genotype 3 , although genotype 4 was the most common genotype in northern Europe. Our small numbers preclude firm conclusions on genotype distribution [28]. Among HCV monoinfected children in the Italian Observatory Study, genotype 1 and genotype 2 were prevalent among adolescents, but infections with genotype 3 and genotype 4 were increasing [29].

It is expected that most children becoming HCV-infected in Europe will develop chronic infection, with around $7-20 \%$ experiencing spontaneous viral clearance $[29,30]$. The limited literature available on HIV/HCV coinfected children suggests that they may be less likely to spontaneously clear HCV than adults or than monoinfected children [7]. Among children with chronic $\mathrm{HCV}$ monoinfection, 2-3\% are expected to progress to cirrhosis in childhood [29]. As probability of liver fibrosis generally increases with age and duration of infection, young adults with HCV acquired vertically or in early childhood may be at risk of end-stage liver disease in early adulthood [31,32]. However, understanding of liver fibrosis progression in childhood and beyond in individuals with vertically or childhood-acquired $\mathrm{HCV}$ is incomplete. Mohan et al. [33] found that 30\% of HCV monoinfected children had more severe fibrosis in a repeat biopsy conducted on average 6 years after their first, demonstrating that liver fibrosis does progress in childhood; other studies show that some children can progress rapidly, developing severe fibrosis after relatively short durations of HCV infection [34,35].

Questions regarding rates of and risk factors for hepatic fibrosis progression in $\mathrm{HIV} / \mathrm{HCV}$ coinfected adults also remain $[36,37]$. In one study, among nearly $300 \mathrm{HIV} /$ HCV coinfected adults with repeat liver biopsies, 34\% had progression of at least one METAVIR stage over a median of 2.5 years despite $86 \%$ having no or minimal fibrosis at their first biopsy; risk factors for progression included elevated liver enzymes, obesity and hepatic steatosis, but not ART, $\mathrm{CD}^{+}{ }^{+}$cell count or HIV RNA levels [36]. In the present study, of the 17 patients with liver biopsies, $40 \%$ had bridging fibrosis and one went on to develop cirrhosis. However, these biopsy results should be interpreted cautiously due to small numbers and potential bias. We were able to calculate APRI and FIB-4 scores for around half of our study population, and transient elastography results were available for $42 \%$ of our study population but the value of these scores and of transient elastography has not yet been established in children.

More than half of our participants had raised ALT/AST at their most recent visit, higher than the 30\% reported for HCV monoinfection in the European Paediatric Hepatitis C Network (EPHN) [30]. A Spanish study also reported higher ALT levels in HIV-coinfected versus monoinfected children [7]. Around $40 \%$ of our study population had hepatomegaly and/or splenomegaly during the previous year, compared with $10 \%$ reported in the EPHN [30]; this may be partly explained by the larger numbers of participants with nonvertically acquired infection in our study, who were more likely to have hepatomegaly than vertically infected children and young people.

Historical cohorts of HCV monoinfected children present a clinical picture of a generally mild disease in terms of symptoms, laboratory and histopathology findings [29,30]. Our findings suggest worse liver disease in $\mathrm{HIV} / \mathrm{HCV}$ coinfected children and young people than in those with HCV monoinfection [29,32], consistent with adult studies $[1,5,36]$. Chronic HCV infection in the context of HIV coinfection may thus be considered as a potentially aggressive infection associated with severe and rapidly progressing liver damage. We found that liver enzyme elevations at the most recent clinic visit were significantly more common among nonvertically infected patients. This group also had greater probability of significant fibrosis according to APRI score, despite shorter duration of HCV infection. Future research using longitudinal data, accounting for other factors associated with development of liver fibrosis, is required.

Regarding HIV disease, most patients had previously experienced moderate or severe clinical symptoms, but most had no or mild immunosuppression at their most recent visit. The finding that three-quarters of those treated had undetectable HIV RNA load is similar to other paediatric HIV cohorts [14,38]. It is debatable whether HCV progression is modified where HIV infection is well controlled; adult studies have shown increased risk of nonliver-related morbidity and mortality in $\mathrm{HCV}$ coinfected individuals due to persistent inflammation and immune activation $[1,5]$, providing the rationale to treat $\mathrm{HCV}$ in this population as early as possible.

Current standard of care for paediatric HCV treatment remains pegIFN/RBV as DAAs have not yet been licensed for paediatric use [39]. Current guidelines recommend that treatment with pegIFN/RBV is considered for children with persistently elevated liver enzymes and/or liver fibrosis [34]. Adult trials show that $\mathrm{HIV} / \mathrm{HCV}$ coinfected individuals do as well, or even better in achieving SVR after DAA treatment than HCV-monoinfected persons [6,40]. Our findings, together with a previous small case series [8], demonstrate worse outcomes with pegIFN/RBV in children and young people with $\mathrm{HIV} / \mathrm{HCV}$ coinfection versus $\mathrm{HCV}$ monoinfection, particularly for genotype 1 and genotype $4[41,42]$. In a separate analysis, we showed that HCV treatment coverage in this population varied substantially by country, with the highest treatment rates in Russia (61\%), whereas no children in some countries had been 
treated. Patients were significantly more likely to be treated if they had advanced fibrosis as defined by transient elastography (e.g. five-fold increased odds of treatment for patients with $\geq 9.6$ versus $\leq 7.2 \mathrm{kPa}$ ) and if they were aged more than 18 years [43].

The current study was limited by its cross-sectional, retrospective design and the observational data, which resulted in missing data for some variables and limited details regarding transient elastography and liver biopsy methodology, which were carried out and interpreted as per routine practice at the participating cohorts' sites. Interpretation of the liver biopsy results must take into account the fact that the 17 patients with biopsies were from eight cohorts and biopsies were assessed by different pathologists using different grading and staging systems. Duration of HCV infection will have been underestimated in patients with nonvertical mode of transmission as diagnosis date was taken as a proxy. Interpretation of the APRI, FIB-4 and transient elastography results should allow for the absence of large paediatric HCV studies validating these markers.

The current study is the first one describing a large population of HIV/HCV coinfected children and young people across Europe. As clinical management of coinfected children has previously relied on extrapolation from adult studies, our findings will contribute to better understanding of this coinfection in childhood. We describe a substantial proportion of $\mathrm{HIV} / \mathrm{HCV}$ coinfected children and young people with progressive liver disease, with low response to standard treatment with pegIFN/RBV among the minority treated to date. Considering this, the improved life expectancy in HIV-infected children and the excellent outcomes in adults with $\mathrm{HIV} / \mathrm{HCV}$ infection treated with DAAs, these observations support the need of $\mathrm{HIV} / \mathrm{HCV}$ coinfected children for HCV treatment.

\section{Acknowledgements}

\section{European Paediatric HIV/HCV Co-infection Study Group in the European Pregnancy and Paediatric HIV Cohort Collaboration (EPPICC) in EuroCoord}

The current work was supported by funding from the EU Seventh Framework Programme (FP7/2007-2013) under EuroCoord grant agreement [no. 260694] and additional funding from Janssen. Authors have received financial support for other studies from UK MRC, Public Health England, IMI, Abbvie, ViiV and Gilead. No other potential conflicts of interest to declare.

Funding: This work was supported by funding from the EU Seventh Framework Programme (FP7/2007-2013) under EuroCoord grant agreement [no. 260694] and additional funding from Janssen.
Authors: The European Paediatric HIV/HCV Coinfection Study Group consists of the following (ordered by project team first and then alphabetically by country of cohort): Claire Thorne (University College London (UCL) Institute of Child Health), Anna Turkova (MRC Clinical Trials Unit at UCL), Giuseppe Indolfi, Elisabetta Venturini (Meyer Children's University-Hospital of Florence), Carlo Giaquinto (University of Padova); Belgium: Hospital St Pierre Cohort, Brussels: Tessa Goetghebuer, Marc Hainaut, Evelyne Van Der Kelen; Germany: German Pediatric and Adolescent HIV Cohort: Christoph Königs, Kathleen Mantzsch, Ulrich Baumann; Italy: Italian Register for HIV-infection in Children: Maurizio de Martino, Luisa Galli (Meyer Children's University-Hospital of Florence), participating sites: Vania Giacomet (Luigi Sacco Hospital, University of Milan), Laura Ambra Nicolini (University of Genoa, IRCCS AOU San Martino-IST), Filippo Del Puente (University of Genoa, IRCCS AOU San Martino-IST), Clara Gabiano (Turin), Alfredo Guarino (Naples), Silvia Martinazzi (Brescia), Angela Miniaci (Bologna); Poland: Medical University Warsaw/Regional Hospital of Infectious Disease cohort: Sabina Dobsz, Magdalena Marczynska; Romania: 'Victor Babes' Hospital Cohort, Romania: Luminita Ene, Dan Duiculescu; Russia: Republican Hospital of Infectious Diseases (RHID), St Petersburg cohort: Milana Miloenko, Konstantin Dodonov, Inga Latysheva, Evgeny Voronin; Spain: Cohort of the Spanish Paediatric HIV Network - rest of Spain (CoRISPE-1): Pablo Rojo (Hospital 12 de Octubre, Universidad Complutense, Madrid), Jose Tomas Ramos (Hospital Clínico), Marisa Navarro, Santiago Jimenez de Ory and Talia Sainz (Hospital Gregorio Marañón), Maria J Mellado and Miluca García (Hospital La Paz), Carlos Pérez (Hospital de Cabueñes), David Moreno and Esmeralda Nuñez (Hospital Carlos Haya), Mercedes Gracia (Hospital Clínico Zaragoza), Pedro Terol (Hospital Virgen de la Macarena), Olaf Neth and Lola Falcon (Hospital Virgen del Rocío), Carmen Otero and Elena Rincón (Hospital La Fe), César Gavilán (Hospital San Juan Alicante), Carmen López (Hospital de Castellón), Juan Luis Santos (Hospital Virgen de las Nieves), Jose Couceiro (Hospital de Pontevedra); Cohort of the Spanish Paediatric HIV Network - Catalunya (CoRISPEcat): Antoni Noguera-Julian (Hospital Sant Joan de Déu, Universitat de Barcelona) and Claudia Fortuny, Pere Soler-Palacin, Maria Espiau, Antonio Mur, Maria T. Coll, Maria T. Valmanya, Luis Mayol, María J. Méndez, Carlos Rodrigo, Joaquín Escribano, Neus Rius, Núria Rovira, Olga Calavia, Lourdes García, Valentí Pineda and Antoni Soriano-Arandes; Switzerland: Swiss Mother and Child HIV Cohort Study (MoCHiV): Christoph Rudin, Andrea Duppenthaler; United Kingdom and Ireland Collaborative HIV Paediatric Study (CHIPS): Ali Judd (MRC Clinical Trials Unit at UCL); Ukraine: Ukraine Cohort of HIV-infected children: Ruslan Malyuta (PPAI, Odessa), Alla Volokha (Shupyk National Medical Academy of Postgraduate Education, Kiev), 
Irina Raus (Kiev City Centre for HIV/AIDS), T Kaleeva, Y Baryshnikova (Odessa Regional Centre for HIV/ AIDS), Svetlana Soloha (Donetsk Regional Centre for HIV/AIDS), N Bashkatova (Mariupol AIDS Centre), O Glutshenko, Z Ruban (Mykolaiv Regional Centre for HIV/AIDS), Natalia Primak (Kryvyi Rih City Centre for HIV/AIDS), Galina Kiseleva (formerly Simferopol Centre for HIV/AIDS).

\section{EuroCoord acknowledgements}

EuroCoord Executive Board: Fiona Burns, University College London, UK; Geneviève Chêne, University of Bordeaux, France; Dominique Costagliola (Scientific Coordinator), Institut National de la Santé et de la Recherche Médicale, France; Carlo Giaquinto, Fondazione PENTA, Italy; Jesper Grarup, Region Hovedstaden, Denmark; Ole Kirk, Region Hovedstaden, Denmark; Laurence Meyer, Institut National de la Santé et de la Recherche Médicale, France; Heather Bailey, University College London, UK; Alain Volny Anne, European AIDS Treatment Group, France; Alex Panteleev, St. Petersburg City AIDS Centre, Russian Federation; Andrew Phillips, University College London, UK, Kholoud Porter, University College London, UK; Claire Thorne, University College London, UK.

EuroCoord Council of Partners: Jean-Pierre Aboulker, Institut National de la Santé et de la Recherche Médicale, France; Jan Albert, Karolinska Institute, Sweden; Silvia Asandi, Romanian Angel Appeal Foundation, Romania; Geneviève Chêne, University of Bordeaux, France; Dominique Costagliola (chair), INSERM, France; Antonella d'Arminio Monforte, ICoNA Foundation, Italy; Stéphane De Wit, St. Pierre University Hospital, Belgium; Peter Reiss, Stichting HIV Monitoring, Netherlands; Julia Del Amo, Instituto de Salud Carlos III, Spain; José Gatell, Fundació Privada Clínic per a la Recerca Bíomèdica, Spain; Carlo Giaquinto, Fondazione PENTA, Italy; Osamah Hamouda, Robert Koch Institut, Germany; Igor Karpov, University of Minsk, Belarus; Bruno Ledergerber, University of Zurich, Switzerland; Jens Lundgren, Region Hovedstaden, Denmark; Ruslan Malyuta, Perinatal Prevention of AIDS Initiative, Ukraine; Claus Møller, Cadpeople A/S, Denmark; Kholoud Porter, University College London, United Kingdom; Maria Prins, Academic Medical Centre, Netherlands; Aza Rakhmanova, St. Petersburg City AIDS Centre, Russian Federation; Jürgen Rockstroh, University of Bonn, Germany; Magda Rosinska, National Institute of Public Health, National Institute of Hygiene, Poland; Manjinder Sandhu, Genome Research Limited; Claire Thorne, University College London, UK; Giota Touloumi, National and Kapodistrian University of Athens, Greece; Alain Volny Anne, European AIDS Treatment Group, France.

EuroCoord External Advisory Board: David Cooper, University of New South Wales, Australia; Nikos Dedes,
Positive Voice, Greece; Kevin Fenton, Public Health England, USA; David Pizzuti, Gilead Sciences, USA; Marco Vitoria, World Health Organisation, Switzerland.

EuroCoord Secretariat: Silvia Faggion, Fondazione PENTA, Italy; Lorraine Fradette, University College London, UK; Richard Frost, University College London, UK; Andrea Cartier, University College London, UK; Dorthe Raben, Region Hovedstaden, Denmark; Christine Schwimmer, University of Bordeaux, France; Martin Scott, UCL European Research \& Innovation Office, UK.

\section{Conflicts of interest}

There are no conflicts of interest.

\section{References}

1. Soriano $V$, Barreiro $P$, Sherman KE. The changing epidemiology of liver disease in HIV patients. AIDS Rev 2013; 15:25-31.

2. Danta M, Semmo N, Fabris P, Brown D, Pybus OG, Sabin CA, et al. Impact of HIV on host-virus interactions during early hepatitis $\mathrm{C}$ virus infection. Asian J Infect Dis 2008; 197:1558-1566.

3. Soto B, Sanchez-Quijano A, Rodrigo L, del Olmo JA, GarciaBengoechea M, Hernandez-Quero J, et al. Human immunodeficiency virus infection modifies the natural history of chronic parenterally-acquired hepatitis $C$ with an unusually rapid progression to cirrhosis. I Hepatol 1997; 26:1-5.

4. Greub G, Ledergerber B, Battegay M, Grob P, Perrin L, Furrer H, et al. Clinical progression, survival, and immune recovery during antiretroviral therapy in patients with HIV-1 and hepatitis C virus coinfection: the Swiss HIV Cohort Study. Lancet 2000; 356:1800-1805.

5. Lee $\mathrm{MH}$, Yang $\mathrm{HI}$, Lu SN, Jen $\mathrm{CL}$, You SL, Wang LY, et al. Chronic hepatitis $\mathrm{C}$ virus infection increases mortality from hepatic and extrahepatic diseases: a community-based longterm prospective study. I Infect Dis 2012; 206:469-477.

6. Chung RT, Baumert TF. Curing chronic hepatitis C: the arc of a medical triumph. N Engl J Med 2014; 370:1576-1578.

7. Claret-Teruel G, Noguera-Julian A, Esteva C, Munoz-Almagro C, Sanchez E, Jimenez R, et al. Impact of human immunodeficiency virus coinfection on the progression of mother-tochild transmitted hepatitis $\mathbf{C}$ virus infection. Pediatr Infect Dis / 2011; 30:801-804.

8. Rosso R, Di Biagio A, Mikulska M, Nicco E, Bernardini C, Viscoli C. Safety and efficacy of pegylated interferon and ribavirin in adolescents with human immunodeficiency virus and hepatitis C virus acquired perinatally. I Med Virol 2010; 82:1110-1114.

9. Polis $\mathrm{CB}$, Shah $\mathrm{SN}$, Johnson KE, Gupta A. Impact of maternal HIV coinfection on the vertical transmission of hepatitis $C$ virus: a meta-analysis. Clin Infect Dis 2007; 44:1123-1131.

10. England K, Thorne C, Newell ML. Vertically acquired paediatric coinfection with HIV and hepatitis C virus. Lancet Infect Dis 2006; 6:83-90.

11. England K, Thorne C, Castelli-Gattinara G, Vigano A, El Mehabresh MI, Newell ML. HIV and HCV progression in parenterally coinfected children. Curr HIV Res 2009; 7:346-353.

12. Busza J, Douthwaite M, Bani R, Scutelniciuc O, Preda M, Simic D. Injecting behaviour and service use among young injectors in Albania, Moldova, Romania and Serbia. Int / Drug Policy 2013; 24:423-431.

13. Chatterjee S, Tempalski B, Pouget ER, Cooper HL, Cleland CM, Friedman SR. Changes in the prevalence of injection drug use among adolescents and young adults in large U.S. metropolitan areas. AIDS Behav 2011; 15:1570-1578.

14. Judd A. Early antiretroviral therapy in HIV-1-infected infants, 1996-2008: treatment response and duration of first-line regimens. AIDS 2011; 25:2279-2287.

15. Kissin DM, Zapata L, Yorick R, Vinogradova EN, Volkova GV, Cherkassova E, et al. HIV seroprevalence in street youth, St. Petersburg, Russia. AIDS 2007; 21:2333-2340. 
16. Indolfi G, Azzari C, Resti M. Perinatal transmission of hepatitis C virus. / Pediatr 2013; 163:1549-1552.

17. Caldwell MB, Oxtoby MJ, Simonds RJ, Lindegren ML, Rogers MF. 1994 Revised classification system for human immunodeficiency virus infection in children less than $\mathbf{1 3}$ years of age. MMWR Recomm Rep 1994; 43:1-10.

18. Division of AIDS National Institute of AIDS and Infectious Disease. National Institutes of Health, Department of Health and Human Services. US Division of AIDS (DAIDS) table for grading the severity of adult and paediatric adverse events. Version 2.0, November 2014. Bethesda, US: Division of AIDS National Institute of AIDS and Infectious Disease, National Institutes of Health, Department of Health and Human Services; 2014.

19. Shiha GZ. Ishak versus METAVIR: terminology, convertibility and correlation with laboratory changes in chronic hepatitis $C$. In: Takahash H. editor. Liver biopsy Rijeka, Croatia: InTech; 2011.

20. Sterling RK, Lissen E, Clumeck N, Sola R, Correa MC, Montaner $\mathrm{J}$, et al. Development of a simple noninvasive index to predict significant fibrosis in patients with HIV/HCV coinfection. Hepatology 2006; 43:1317-1325.

21. Al-Mohri H, Murphy T, Lu Y, Lalonde RG, Klein MB. Evaluating liver fibrosis progression and the impact of antiretroviral therapy in HIV and hepatitis $C$ coinfection using a noninvasive marker. I Acquir Immune Defic Syndr 2007; 44:463-469.

22. Wai CT, Greenson JK, Fontana RJ, Kalbfleisch JD, Marrero JA, Conjeevaram $\mathrm{HS}$, et al. A simple noninvasive index can predict both significant fibrosis and cirrhosis in patients with chronic hepatitis C. Hepatology 2003; 38:518-526.

23. McGoogan KE, Smith PB, Choi SS, Berman W, Jhaveri R. Performance of the AST-to-platelet ratio index as a noninvasive marker of fibrosis in pediatric patients with chronic viral hepatitis. I Pediatr Gastroenterol Nutr 2010; 50:344-346.

24. Floridia M, Tamburrini E, Anzidei G, Tibaldi C, Muggiasca ML, Guaraldi $G$, et al. Declining HCV seroprevalence in pregnant women with HIV. Epidemiol Infect 2010; 138:1317-1321.

25. Foster C, Judd A, Tookey P, Tudor-Williams G, Dunn D, Shingadia D, et al. Young people in the United Kingdom and Ireland with perinatally acquired HIV: the pediatric legacy for adult services. AIDS Patient Care STDS 2009; 23:159-166.

26. Kissin DM, Mandel MG, Akatova N, Belyakov NA, Rakhmanova AG, Voronin EE, et al. Five-year trends in epidemiology and prevention of mother-to-child HIV transmission, St. Petersburg, Russia: results from perinatal HIV surveillance. BMC Infect Dis 2011; 11:292.

27. Bailey H, Townsend CL, Semenenko I, Malyuta R, Cortina-Borja $M$, Thorne C. Impact of expanded access to combination antiretroviral therapy in pregnancy: results from a cohort study in Ukraine. Bull World Health Organ 2013; 91:491-500.

28. Messina JP, Humphreys I, Flaxman A, Brown A, Cooke GS, Pybus OG, et al. Global distribution and prevalence of hepatitis C virus genotypes. Hepatology 2015; 61:77-87.

29. Bortolotti F, Verucchi G, Camma C, Cabibbo G, Zancan L, Indolfi $\mathrm{G}$, et al. Long-term course of chronic hepatitis $C$ in children: from viral clearance to end-stage liver disease. Gastroenterology 2008; 134:1900-1907.
30. European Paediatric Hepatitis C Virus Network. Three broad modalities in the natural history of vertically acquired hepatitis C virus infection. Clin Infect Dis 2005; 41:45-51.

31. Guido M, Bortolotti F, Leandro G, Jara P, Hierro L, Larrauri J, et al. Fibrosis in chronic hepatitis $\mathbf{C}$ acquired in infancy: is it only a matter of time? Am J Gastroenterol 2003; 98:660-663.

32. Goodman ZD, Makhlouf HR, Liu L, Balistreri W, GonzalezPeralta RP, Haber B, et al. Pathology of chronic hepatitis C in children: liver biopsy findings in the Peds-C Trial. Hepatology 2008; 47:836-843.

33. Mohan P, Barton BA, Narkewicz MR, Molleston JP, GonzalezPeralta RP, Rosenthal $P$, et al. Evaluating progression of liver disease from repeat liver biopsies in children with chronic hepatitis C: a retrospective study. Hepatology 2013; 58:15801586.

34. Mack CL, Gonzalez-Peralta RP, Gupta N, Leung D, Narkewicz MR, Roberts EA, et al. NASPGHAN practice guidelines: diagnosis and management of hepatitis $C$ infection in infants, children, and adolescents. I Pediatr Gastroenterol Nutr 2012; 54:838-855.

35. Badizadegan K, Jonas MM, Ott MJ, Nelson SP, Perez-Atayde AR. Histopathology of the liver in children with chronic hepatitis $C$ viral infection. Hepatology 1998; 28:1416-1423.

36. Konerman MA, Mehta SH, Sutcliffe CG, Vu T, Higgins $Y$, Torbenson MS, et al. Fibrosis progression in human immunodeficiency virus/hepatitis $\mathrm{C}$ virus coinfected adults: prospective analysis of 435 liver biopsy pairs. Hepatology 2014; 59:767-775.

37. Rollet-Kurhajec KC, Moodie EE, Walmsley S, Cooper C, Pick N, Klein MB. Hepatic fibrosis progression in HIV-hepatitis $C$ virus co-infection - the effect of sex on risk of significant fibrosis measured by aspartate-to-platelet ratio index. PloS One 2015; 10:e0129868.

38. Kekitiinwa A, Lee KJ, Walker AS, Maganda A, Doerholt K, Kitaka $\mathrm{SB}$, et al. Differences in factors associated with initial growth, CD4, and viral load responses to ART in HIV-infected children in Kampala, Uganda, and the United Kingdom/Ireland. J Acquir Immune Defic Syndr 2008; 49:384-392.

39. Thorne C, Indolfi G, Turkova A, Giaquinto C, Nastouli E. Treating hepatitis $C$ virus in children: time for a new paradigm. J Viral Eradication 2015; 1:203-205.

40. Macias J, Neukam K, Merchante N, Pineda JA. Latest pharmacotherapy options for treating hepatitis C in HIV-infected patients. Expert Opin Pharmacother 2014; 15:1837-1848.

41. Druyts E, Thorlund K, Wu P, Kanters S, Yaya S, Cooper CL, et al. Efficacy and safety of pegylated interferon alfa-2a or alfa-2b plus ribavirin for the treatment of chronic hepatitis $C$ in children and adolescents: a systematic review and meta-analysis. Clin Infect Dis 2013; 56:961-967.

42. Abdel-Hady M, Bansal S, Davison SM, Brown M, Tizzard SA, Mulla $S$, et al. Treatment of chronic viral hepatitis $C$ in children and adolescents: UK experience. Arch Dis Child 2014; 99:505510.

43. Turkova A, Giacomet V, Goetghebuer T, Miloenko M, Nicolini LA, Noguera-Julian A, et al. HCV treatment in children and young adults with HIV/HCV co-infection in Europe. / Viral Eradication 2015; 1:179-184. 